\title{
Hot Deformation Stability of Extruded AZ61 Magnesium Alloy Using Different Instability Criteria
}

\author{
Ju-Qiang Li ${ }^{1} \cdot J_{u a n} \mathrm{Liu}^{1} \cdot$ Zhen-Shan Cui $^{1}$
}

Received: 6 July 2015/Revised: 29 September 2015/Published online: 23 November 2015

(C) The Chinese Society for Metals and Springer-Verlag Berlin Heidelberg 2015

\begin{abstract}
The hot deformation stability of extruded AZ61 magnesium alloy was investigated by means of hot compression tests at the temperature range of $250-400{ }^{\circ} \mathrm{C}$ and strain rate range of $0.001-1 \mathrm{~s} \mathrm{~s}^{-1}$. The 3D instability maps considering the effect of strain were developed to delineate the regions of unstable flow on the basis of Jonas's, Semiatin's, Prasad's, Murty's, Gegel's and Alexander's criteria. Since non-uniform deformation occurs due to the initial microstructure inhomogeneity, the friction, etc., finite element simulations were performed to determine the position of the specimens which can mostly represent the preset deformation parameter. Detailed microstructural investigation on such position was carried out to examine the validity of the instability maps, and the results indicate that for extruded AZ61 magnesium alloy: (1) Jonas's and Semiatin's criteria conservatively predict the instability regions; (2) Gegel's and Alexander's criteria inadequately predict the instability regions; (3) Prasad's and Murty's criteria provide more effective predictions of the instability regions than Jonas's, Semiatin's, Gegel's and Alexander's criteria.
\end{abstract}

KEY WORDS: Magnesium alloy; Hot deformation stability; Finite element simulation; Microstructure

\section{Introduction}

Magnesium alloys have high potential for use as structural materials in automotive and aerospace industries owing to their low density, good damping capacity and excellent machinability [1]. $\mathrm{Mg}-\mathrm{Al}-\mathrm{Zn}$ alloys are the currently most widely used magnesium-based alloys, and among them, AZ61 alloy is especially attractive because of its good combination of strength and ductility [2]. Unfortunately, AZ61 alloy generally exhibits low formability at room temperature due to the limited number of slip systems associated with the hexagonal close-packed crystal

Available online at http://link.springer.com/journal/40195.

\section{Juan Liu}

liujuan@sjtu.edu.cn

1 National Engineering Research Center for Die and Mold CAD, School of Materials Science and Engineering, Shanghai Jiao Tong University, Shanghai 200030, China structure [3]. In this sense, the investigation on the hot deformation behavior of AZ61 alloy is of great importance for obtaining wrought components without deformation defects.

The term "flow instability" refers to a situation in which a small local deviation from spatially uniform deformation grows with time [4]. Since its microstructural manifestations such as adiabatic shear bands, localized shear and Lüders bands are detrimental to the mechanical properties of the components, flow instability arising during processing must be avoided [5]. In order to predict the occurrence of flow instability, various criteria have been proposed. Jonas et al. [6] were the pioneers to derive the instability criterion for the deformation under compressive loading. Following the report suggested by Jonas, Semiatin and Lahoti [7] introduced a phenomenological criterion on the basis of the microstructural observations in titanium and its alloys. Prasad et al. [8] have arrived at a continuum instability criterion by integrating the dynamic materials model (DMM) with Ziegler's extremum principles of 
irreversible thermodynamic. However, Prasad's instability criterion was derived under the power law assumption which is not suitable for complicated alloy systems. On this basis, Murty and Rao [9] proposed a simplified instability criterion that can be applicable for any type of flow curve. According to continuum mechanics, thermodynamics and stability theory, Gegel et al. [10] treated $\eta$ and $s$ as Lyapunov functions and developed a set of criteria for the stable material flow. Similarly, Alexander [11] treated $m$ and $s$ as Lyapunov functions and proposed another set of stable criteria. Although these criteria have provided helpful guideline in evaluating the hot deformation stability of metals and alloys, there is no unique instability criterion that can be applied to delineate the stability and instability region for all kinds of materials until now. Detailed microstructural observations are still essential in evaluating the suitability of an instability criterion on the studied alloy.

Up to now, compression tests are widely used to determine the flow stress of the material and evaluate the microstructural evolution in metal forming processing. During the compression test, the specimen tends to become barrel-shaped due to friction at the specimen-die interface. Although the effect of the friction on the flow stress can be eliminated by the correction method, the effect of the friction on the microstructures could not be eliminated, which means that the deformation conditions at various positions of the specimen have some difference. In order to examine the validity of the instability criterion more accurately, optical investigation should be performed on the position of the specimen which can mostly represent the preset deformation parameter. It is well established that finite element (FE) simulation is an effective method of evaluating the distribution of temperature, strain rate and strain in plastically deforming metals [12]. Thus, such position can be determined by means of FE simulation.

In this paper, the hot deformation stability of extruded AZ61 magnesium alloy was investigated using hot compression tests. The 3D instability maps based on Jonas's, Semiatin's, Prasad's, Murty's, Gegel's and Alexander's criteria were developed to delineate the regions of unstable flow. FE simulations were performed to determine the position of the specimen which can mostly represent the preset deformation condition. The reliability and validity of the instability maps were examined through detailed microstructural observations on such position.

\section{Experimental}

The material used in the present study was received as an extruded rod with the chemical composition of $\mathrm{Mg}-$ $6.01 \mathrm{Al}-0.39 \mathrm{Zn}$ (in wt\%). The initial microstructure of extruded AZ61 magnesium alloy is illustrated in Fig. 1. Cylindrical compression specimens of $10 \mathrm{~mm}$ in diameter and $15 \mathrm{~mm}$ in height were machined from the rod with their axes aligned along the extruded direction. In order to reduce the friction during deformation, a graphite paste was applied to the contacting surface of the specimens and the anvils. The isothermal compression tests were performed using a Gleeble 1500 thermo-mechanical simulator at temperatures of $250,300,350$ and $400{ }^{\circ} \mathrm{C}$ and strain rates of $0.001,0.01,0.1$ and $1 \mathrm{~s}^{-1}$. The specimens were heated to the test temperatures at the rate of $5{ }^{\circ} \mathrm{C} / \mathrm{s}$ and hold for $5 \mathrm{~min}$ before compression. All the specimens were compressed to the true strain of 1.0 and then water-quenched immediately to preserve the microstructure evolved during deformation. For metallographic analysis, the deformed specimens were sectioned in the center along the compression axis. The cut surfaces were mechanically polished using standard techniques and etched in a solution containing $4.2 \mathrm{~g}$ picric acid, $10 \mathrm{~mL}$ acetic acid, $10 \mathrm{~mL}$ water and $70 \mathrm{~mL}$ ethanol.

It is noteworthy that the specimens become barrelshaped due to the contact friction between the specimen and the anvils. In order to eliminate the effect of the friction on the true stress-true strain curves, the flow stress data obtained from the tests should be corrected. The effect of friction can be expressed using the following equation [13]

$\sigma=\frac{P c^{2}}{2[\exp (c)-c-1]}$,

where

$c=\frac{2 \mu r}{h}$.

Here, $\sigma$ is the stress in the absence of friction; $P$ is the measured flow stress; $r$ and $h$ are the instantaneous radius

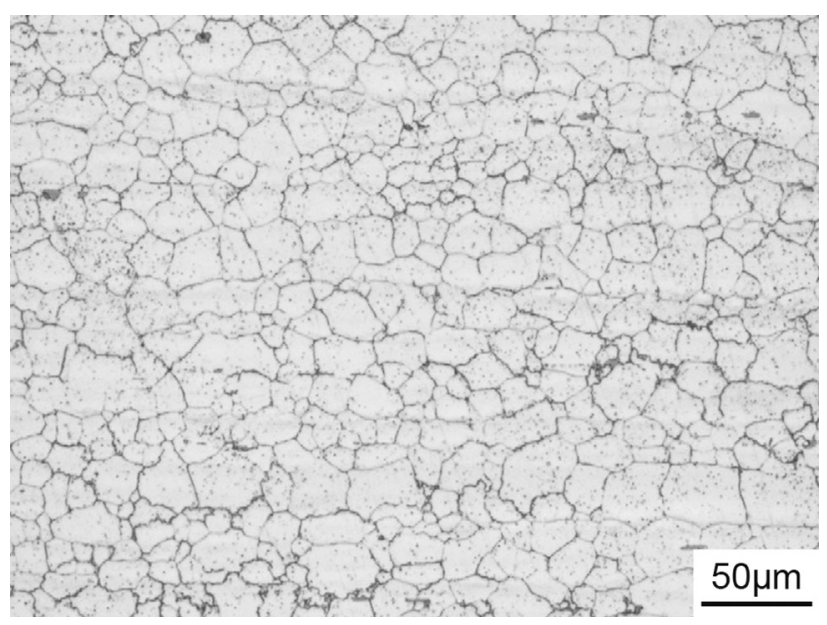

Fig. 1 Initial microstructure of extruded AZ61 magnesium alloy 
and height of the specimen; $\mu$ is the friction coefficient and could be expressed as [14]

$\mu=\frac{(R / H) b}{(4 / \sqrt{3})-(2 b / 3 \sqrt{3})}$,

where

$b=4 \frac{\Delta R}{R} \frac{H}{\Delta H}$,

and

$R=R_{0} \sqrt{\frac{H_{0}}{H}}$.

Here, $b$ is the barreling factor; $\Delta R$ is the difference between the maximum radii and minimum radii of the specimen after deformation; $H$ is the final height of the specimen; and $\Delta H$ is the difference between initial and final heights of the specimen.

\section{Results and Discussion}

\subsection{Flow Behavior}

The true stress-true strain curves of extruded AZ61 magnesium alloy corrected for the friction and obtained at various temperatures and strain rates are shown in Fig. 2. It can be seen from Fig. 2 that the deformation temperature and strain rate have a significant influence on the flow behavior. In general, the flow stress increases with decreasing strain rate at a given deformation temperature, while it decreases with increasing deformation temperature at a given strain rate. It could be also observed from Fig. 2 that all the flow curves exhibit a peak stress at a certain strain, followed by continuous flow softening and finally reaching a steady state. Such flow behavior can be attributed to a competitive procedure between the working hardening and the dynamic softening. At initial deformation stage, the work hardening due to the increase in dislocation density leads to a pronounced increase in flow stress. As deformation proceeds, the dynamic softening gradually counteracts the work hardening, and then, the flow stress decreases with increasing strain $[15,16]$.

\subsection{Determination of the Instability Parameters}

\subsubsection{Jonas's Criterion}

According to Jonas's criterion [6], flow instability under compressive loading will occur if the following condition is satisfied
$\xi_{J}=\frac{\gamma-1}{m}>0$,

where $\gamma$ is the normalized work hardening rate:

$\gamma=\frac{1}{\sigma} \frac{\partial \sigma}{\partial \varepsilon}$

and $m$ is the strain rate sensitivity parameter:

$m=\frac{\partial \ln \sigma}{\partial \ln \dot{\varepsilon}}$.

\subsubsection{Semiation's Criterion}

Semiatin and Lahoti [7] have introduced a phenomenological criterion to demonstrate the combined influence of temperature and strain rate on the flow instability. On the basis of force equilibrium approach, a parameter $\alpha$ was derived to estimate the tendency of materials to form marked or catastrophic strain concentrations, which is given by

$\alpha=-\frac{\gamma}{m}$.

Flow instability should be observed when $\alpha=0$; however, it becomes noticeable when $\alpha$ takes a higher value. Semiation and Lahoti [7] investigated the cross sections of the compressed specimens of titanium alloy after plane strain compression and verified that shear bands occur when the value of $\alpha$ exceeds five. Thus, the phenomenological instability criterion $\left(\xi_{\mathrm{s}}\right)$ can be expressed as

$\xi_{\mathrm{s}}=\alpha-5>0$.

\subsubsection{Prasad's Instability Criterion}

Prasad et al. [17] have developed a continuum instability criterion by integrating Ziegler's extremum principles of irreversible thermodynamic with the dynamic materials model (DMM). As reported by Ziegler [18], a system undergoing large plastic deformation will be unstable if

$\frac{\partial D}{\partial \dot{\varepsilon}}<\frac{D}{\dot{\varepsilon}}$,

where $D$ is the dissipation function. According to the DMM, the power $P$ (per unit volume) absorbed by the work piece during plastic flow consists of two complementary parts: $G$ content and $J$ co-content

$P=\sigma \dot{\varepsilon}=G+J=\int_{0}^{\dot{\varepsilon}} \sigma d \dot{\varepsilon}+\int_{0}^{\sigma} \dot{\varepsilon} d \sigma$,

where the $G$ term represents the power dissipated by plastic work and $J$ is related to the metallurgical mechanisms which occur dynamically to dissipate power. 

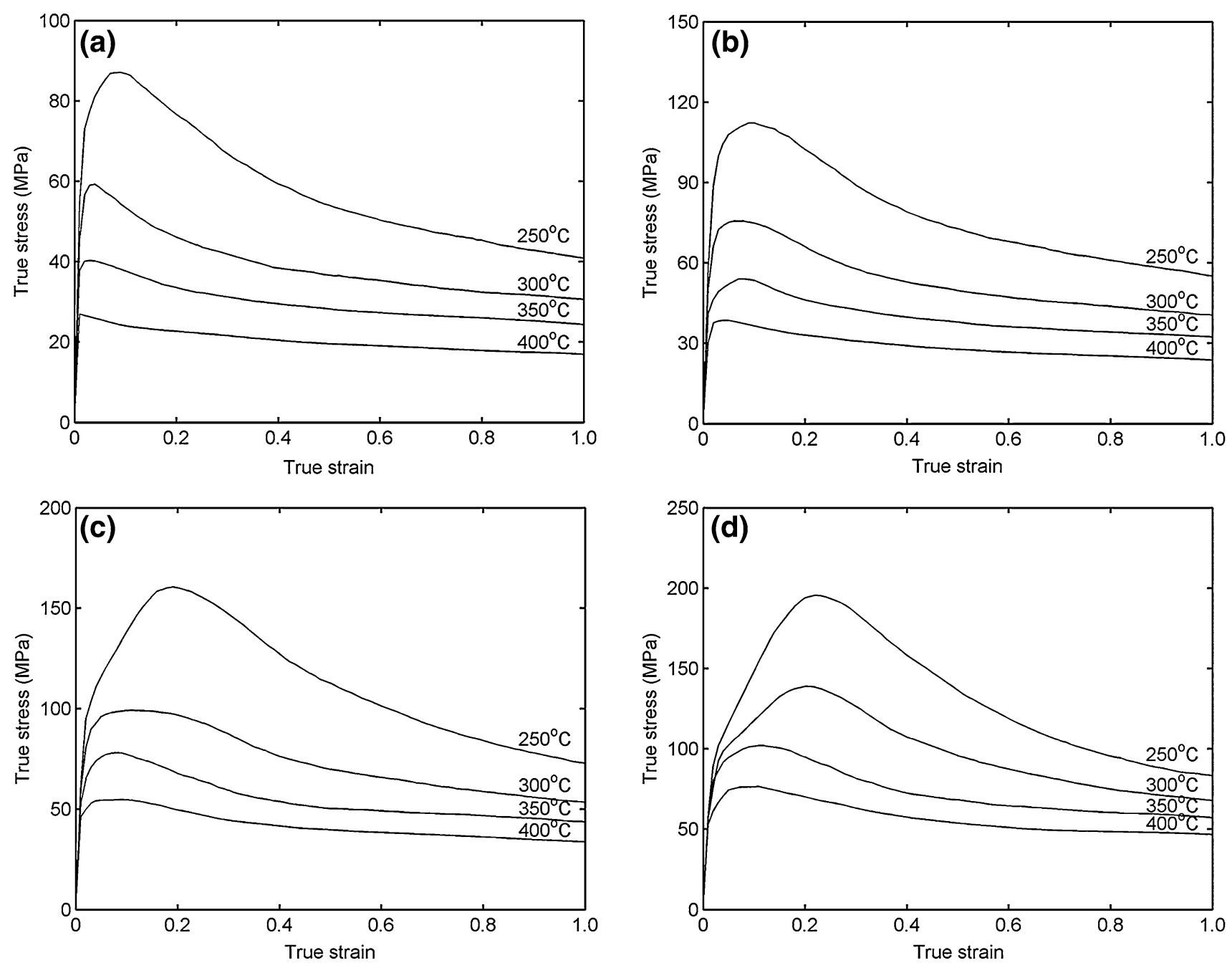

Fig. 2 True stress versus true strain curves of extruded AZ61 magnesium alloy corrected for the friction at $0.001 \mathrm{~s}^{-1} \mathbf{a}, 0.01 \mathrm{~s}^{-1} \mathbf{b}, 0.1 \mathrm{~s}^{-1} \mathbf{c}$, $1 \mathrm{~s}^{-1} \mathbf{d}$

Assuming the power law nature of stress distribution

$$
\sigma=K \dot{\varepsilon}^{m}
$$

the co-content $J$ can be evaluated in terms of $m$ and $P$

$J=\frac{m P}{m+1}$.

Since $J$ represents the dissipation through metallurgical processes, the dissipation function related to metallurgical instability can be replaced by $J$. Then, Eq. (11) becomes

$\frac{\partial J}{\partial \dot{\varepsilon}}<\frac{J}{\dot{\varepsilon}}$.

Substituting the value of $J$ given in Eq. (14) into Eq. (15), the criterion for flow instability can be expressed as

$\xi_{P}=\frac{\partial \ln [m /(m+1)]}{\partial \ln \dot{\varepsilon}}+m<0$.

\subsubsection{Murty's Instability Criterion}

Murty et al. [19, 20] considered that Eq. (16) was derived under the power law assumption, and in this case, Eq. (16) should reduce to $m<0$; otherwise, if the flow stress does not obey the power law, the flow instability condition given in Eq. (16) also becomes erroneous. On this basis, they put forward a simplified instability criterion that can be applicable for any type of flow curve

$\xi_{M}=2 m-\eta<0$,

where $\eta$ is the efficiency of power dissipation and is defined as

$\eta=\frac{J}{J_{\max }}=2\left(1-\frac{1}{\sigma \dot{\varepsilon}} \int_{0}^{\dot{\varepsilon}} \sigma d \dot{\varepsilon}\right)$ 


\subsubsection{Gegel's Stability Criteria}

Gegel et al. [10] treated $\eta$ and $s$ as Lyapunov functions and developed a set of criteria for the stable material flow

$0<m \leq 1$,

$\frac{\partial \eta}{\partial(\ln \dot{\varepsilon})}<0$

$s \geq 1$,

$\frac{\partial s}{\partial(\ln \dot{\varepsilon})}<0$

where $s$ is the temperature sensitivity of the flow stress and is given by

$s=\frac{1}{T} \frac{\partial(\ln \sigma)}{\partial(1 / T)}$.

\subsubsection{Alexander's Stability Criteria}

Alexander et al. [11] treated $m$ and $s$ as Lyapunov functions and proposed another set of stable criteria.

$0<m \leq 1$,

$\frac{\partial m}{\partial(\ln \dot{\varepsilon})}<0$,

$s \geq 1$,

$\frac{\partial s}{\partial(\ln \dot{\varepsilon})}<0$.

\subsection{D Instability Maps}

The 3D instability maps developed according to different instability criteria are shown in Figs. 3a-f, respectively, where the hatched areas represent the regions of unstable flow. The 3D instability map developed as per Jonas's criterion is shown in Fig. 3a. As can be seen from Fig. 3a, the instability regions were identified to occur around $250{ }^{\circ} \mathrm{C} / 1 \mathrm{~s}^{-1}$. Figure $3 \mathrm{~b}$ shows the $3 \mathrm{D}$ instability map developed according to Semiatin's criterion. It is obvious that this instability map exhibits similar instability regions as that of Fig. 3a.

The 3D instability map developed as per Prasad's instability criterion is shown in Fig. 3c. From Fig. 3c, it can be found that the strain has a significant influence on the instability regions. At the strains $<0.5$, the instability map exhibits instability regions at the temperature range of $250-300{ }^{\circ} \mathrm{C}$ and strain rate range of $0.03-1 \mathrm{~s} \mathrm{~s}^{-1}$, whereas at higher strains $(>0.5)$, the instability map exhibits expanded unstable regions at the temperature and strain rate ranges of $300-400{ }^{\circ} \mathrm{C}$ and $0.3-1 \mathrm{~s}^{-1}$. Figure $3 \mathrm{~d}$ illustrates the 3D instability map developed according to Murty's instability criterion. It is apparent that this instability map shows similar instability regions as that of Fig. 3c. A closer look in the two maps reveals that the instability regions of Fig. $3 \mathrm{~d}$ are a little smaller than those revealed in Fig. 3c.

The 3D instability maps developed according to Gegel's and Alexander's stability criteria are shown in Fig. 3e, f, respectively. Obviously, the instability regions revealed in the two maps are almost identical. It could be also observed from Figs. $3 e$ and $f$ that these instability regions reduce significantly with increasing strain. At lower strains, the two maps exhibit wide instability regions over the temperature and strain rate range investigated, whereas at higher strains, the two maps only exhibit instability regions at the temperature and strain rate ranges of: (1) $250-300{ }^{\circ} \mathrm{C}$ and $0.001-0.1 \mathrm{~s}^{-1}$; (2) $300-400{ }^{\circ} \mathrm{C}$ and $0.001-0.01 \mathrm{~s}^{-1}$.

\subsection{FE Simulation}

In the present study, the isothermal compression tests of extruded AZ61 magnesium alloy was simulated using the commercial FE code DEFORM-2D. During simulations, the dimensions of the specimen are set as the same with those used in the experiments and the dies were assumed to be rigid for the sake of simplicity. Other parameters used in the simulation are listed in Table 1.

The FE simulation results of the effective strain distribution at different strokes at the temperature of $300{ }^{\circ} \mathrm{C}$ and strain rate of $0.1 \mathrm{~s}^{-1}$ are shown in Fig. 4. It can be seen that the strain at various positions of the specimen has some difference. In order to study the strain distribution further, four representative points were selected (shown in Fig. 4d). The variations of strain with stroke at these points are presented in Fig. 5. As shown from Fig. 5, only point B undergoes almost the same strain as set in the experiment, while point $A$ undergoes lower strain than the set value, and points $C$ and $D$ undergo higher strains than the set value.

We have examined the same position as point B at other deformation conditions and found that the microstructures at this point undergo almost the same deformation conditions as set in the experiments. The variations of the strain at point $\mathrm{B}$ with the set value under various temperatures and strain rates are shown in Fig. 6. It could be observed that the strains at this point are almost the same with the set values, which means that the strain rates at this point are also almost the same with the set values. Since the adiabatic temperature rise could be ignored at low strain rates $\left(<1 \mathrm{~s}^{-1}\right)$, microstructural investigation can be performed on this point to examine the validity of the instability criteria.

\subsection{Validity of the Instability Maps}

Microstructural investigation was performed on the deformed specimens to examine the validity of the 

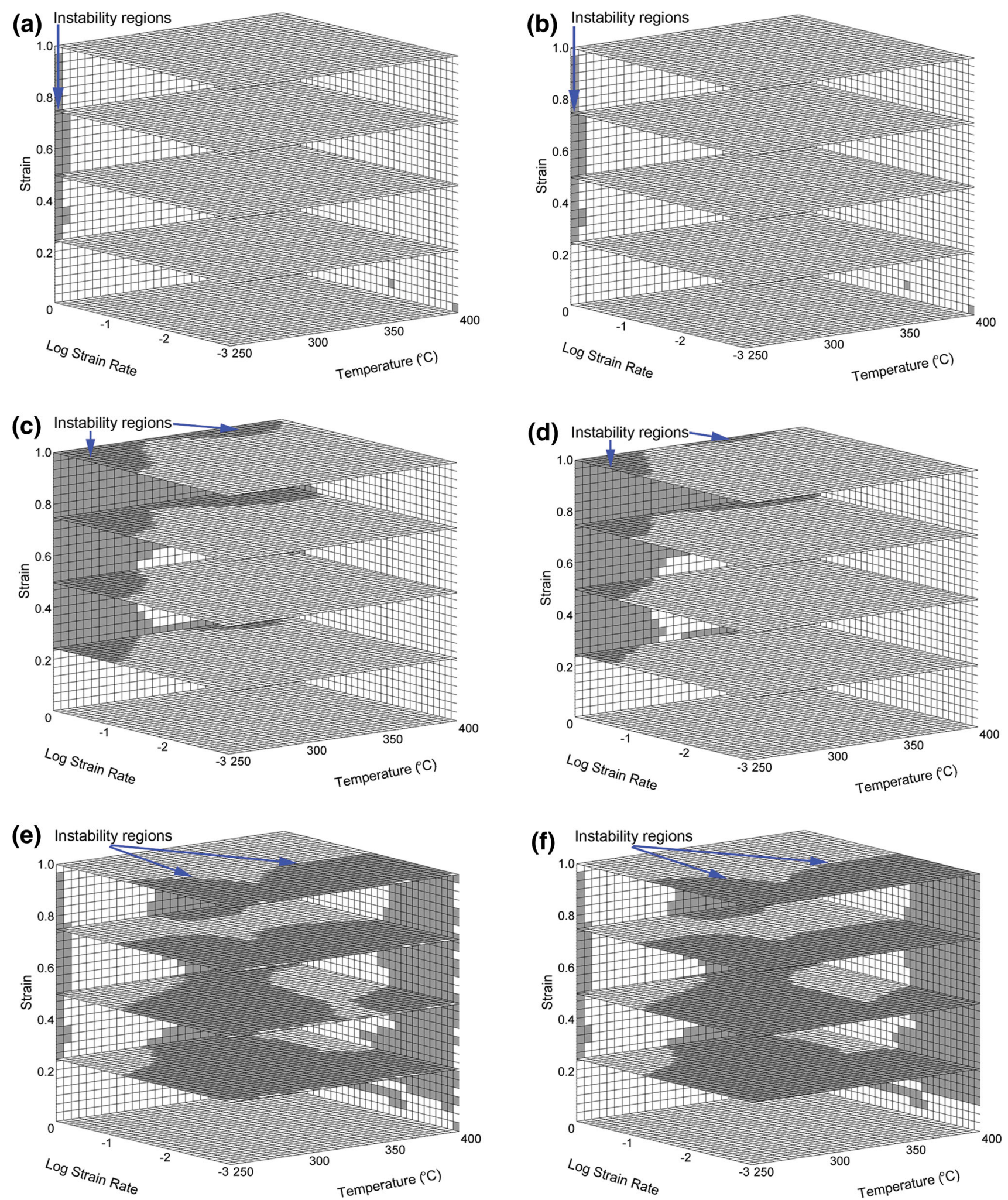

Fig. 3 3D instability maps developed according to Jonas' criterion a, Semiatin's criterion b, Prasad's criterion c, Murty's criterion d, Gegel's criteria e, Alexander's criteria $\mathbf{f}$ 
Table 1 Simulation parameters

\begin{tabular}{ll}
\hline Simulation parameter & Value \\
\hline Young's modulus (MPa) & 43,000 \\
Poisson's ratio & 0.35 \\
Thermal conductivity [W/(m K)] & 79.55 \\
Heat capacity [kJ/(kg K)] & 1.21 \\
Friction coefficient between specimen and die & 0.2 \\
Heat transfer coefficient between specimen and die [W/ & 1100 \\
$\left.\quad\left(\mathrm{~m}^{2} \mathrm{~K}\right)\right]$ & \\
Heat transfer coefficient between specimen and air (W/ & 20 \\
$\left.\quad \mathrm{~m}^{2} \mathrm{~K}\right)$ & 0.1 \\
Emissivity & \\
\hline
\end{tabular}

instability maps. The position selected for investigation has been determined by means of FE simulation (see Sect. 3.4). The microstructures of the specimens deformed at temperatures ranging from 250 to $400{ }^{\circ} \mathrm{C}$ and strain rates ranging from 0.001 to $1.0 \mathrm{~s}^{-1}$ are shown in Fig. 7. From Fig. 7, it can be seen that the micrographs of the specimens deformed at the conditions of $250{ }^{\circ} \mathrm{C} / 0.1 \mathrm{~s} \mathrm{~s}^{-1}, 250$ and $300{ }^{\circ} \mathrm{C} / 1 \mathrm{~s} \mathrm{~s}^{-1}$ exhibit bands of flow localization. The formation of these bands can be attributed to the fact that at lower temperatures and higher strain rates, the heat generated during hot working could not be all dissipated to the colder parts of the body since the time is too short. This may cause a drop in the flow stress, and then, further plastic flow becomes localized [21, 22]. It can also be seen from Fig. 7 that the microstructures of the specimens deformed at other temperatures and strain rates show homogeneous and equiaxed grains. Such microstructures indicate that the material exhibits stable flow under these deformation conditions [23].

Comparing the microstructures (Fig. 7) with the instability regions delineated by Jonas's and Semiatin's criteria (Fig. 3a, b), it can be found that the two criteria

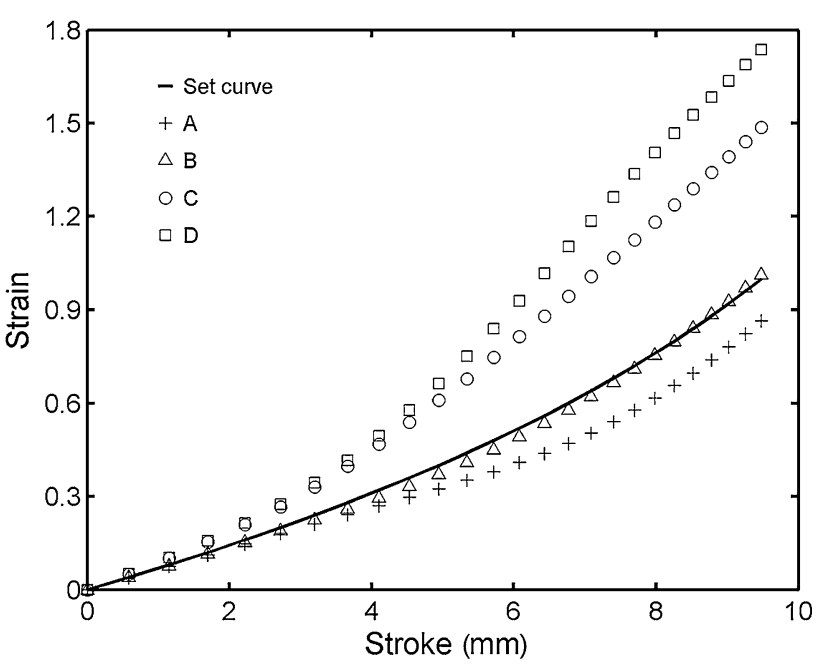

Fig. 5 The variations of the strain with stroke at the selected points

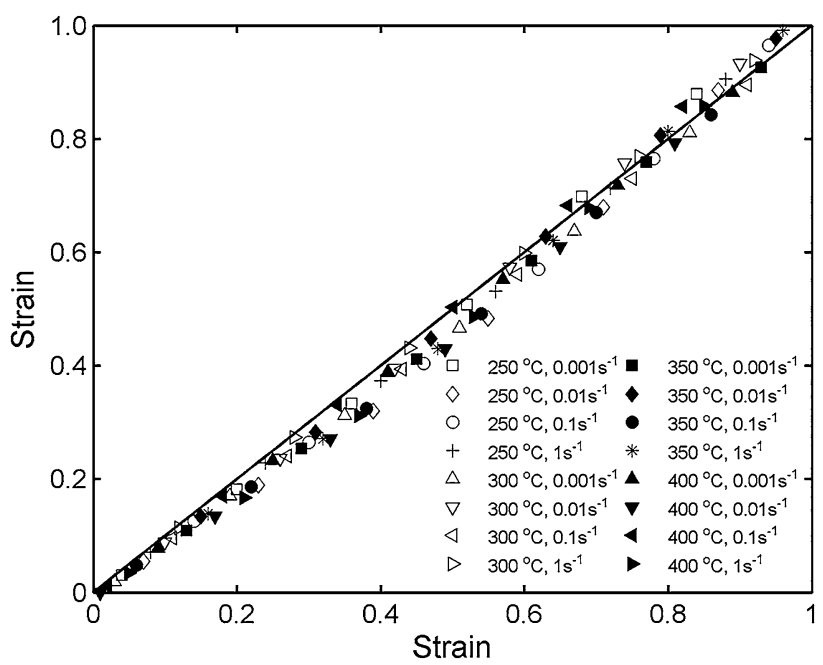

Fig. 6 The variations of the strain at point B with the set value under various temperatures and strain rates

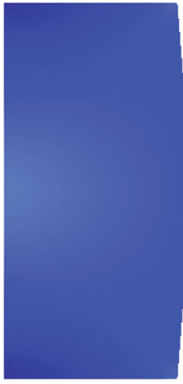

(a)

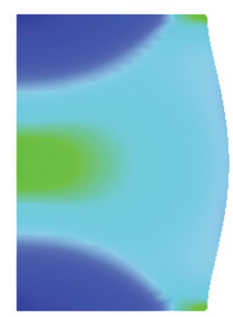

(b)

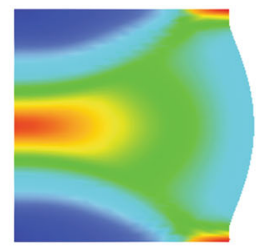

(c)
Effective strain

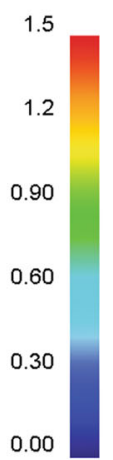

(d)

Fig. 4 Effective strain distributions under the temperature of $300{ }^{\circ} \mathrm{C}$ and strain rate of $0.1 \mathrm{~s}^{-1}$ at strokes of: a $3.20 \mathrm{~mm}, \mathbf{b} 5.72 \mathrm{~mm}, \mathbf{c} 7.70 \mathrm{~mm}$, d $9.48 \mathrm{~mm}$ 


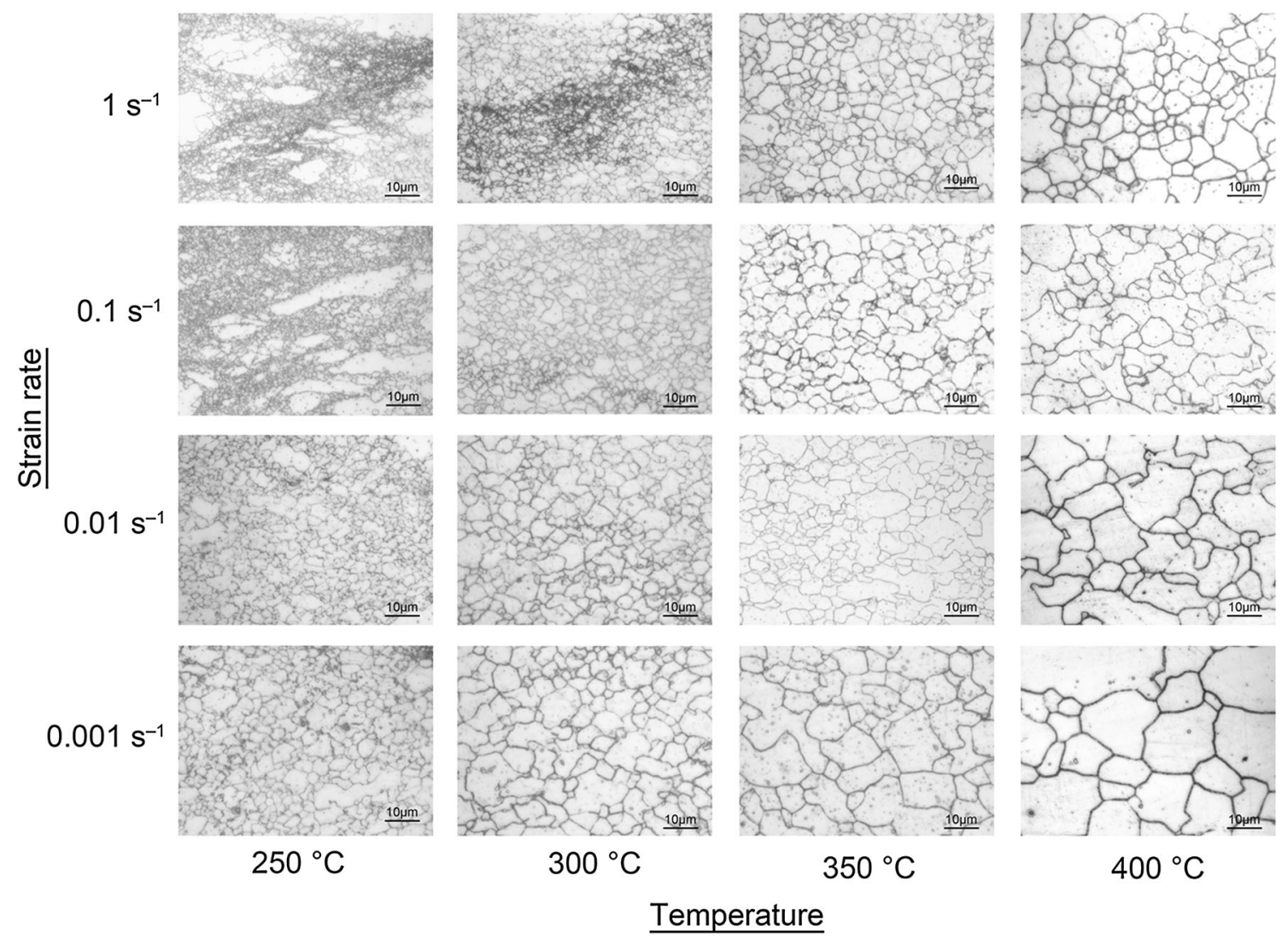

Fig. 7 Microstructures of the specimens deformed at various temperatures and strain rates

conservatively predict the instability regions for the studied alloy. The reason for the conservative prediction of Jonas's criterion may be due to the fact that the occurrence of flow instability as per Jonas's criterion corresponds to the materials that exhibits $\gamma>1$, which is an excessively large flow softening rate $[24,25]$, while the conservative prediction of Semiatin's criterion can be attributed to that the critical value of five in this criterion was determined on the basis of microstructural observations of flow localization in titanium and its alloys, and thus, this value may vary with the materials $[26,27]$.

Through comparing Fig. 7 with Fig. 3c, d, it is found that Prasad's and Murty's instability criteria precisely predict the instability regions at lower temperatures $\left(<300{ }^{\circ} \mathrm{C}\right)$, whereas at temperatures higher than $300{ }^{\circ} \mathrm{C}$, the two instability criteria delineate the instability regions at strain rates higher that $0.1 \mathrm{~s}^{-1}$, where the stable flow was identified to occur as per microstructural investigation. Comparison of Fig. 7 with Fig. 3e, f gives the result that Gegel's and Alexander's criteria inadequately predict the instability regions for the studied alloy. Microstructural investigation has revealed that the flow instability occurs at the lower temperatures and higher strain rates. However, Gegel's and Alexander's criteria do not delineate any regions of unstable flow at this regime.
From the above comparisons of the microstructures with the instability regions delineated by different instability criteria, it can be found that Prasad's and Murty's instability criteria are more effective than Jonas's, Semiatin's, Gegel's and Alexander's criteria in predicting the instability regions for extruded AZ61 alloy, although there exist slight inconsistencies between the predictions of the two criteria and the experimental results.

\section{Conclusions}

The hot deformation stability of extruded AZ61 magnesium alloy has been investigated using hot compression tests at the temperature range of $250-400{ }^{\circ} \mathrm{C}$ and strain rate range of $0.001-1 \mathrm{~s}^{-1}$. The $3 \mathrm{D}$ instability maps based on Jonas's criterion, Semiatin's criterion, Prasad's criterion, Murty's criterion, Gegel's and Alexander's criteria were developed to delineate the regions of unstable flow. Since non-uniform deformation occurs during the compression tests, FE simulations were performed to determine the position of the specimens which can mostly represent the preset deformation parameter. Detailed microstructural investigation on such position was carried out to examine the validity of the instability maps. It has been shown that 
Jonas's and Semiatin's criteria conservatively predict the instability regions, whereas Gegel's and Alexander's criteria inadequately predict the instability regions. Prasad's and Murty's criteria are found to provide more effective predictions of the instability regions than Jonas's, Semiatin's, Gegel's and Alexander's criteria. At temperatures lower than $300{ }^{\circ} \mathrm{C}$ and at the strain rate range of $0.03-1 \mathrm{~s}^{-1}$, the material undergoes flow instability manifesting as flow localization. This region should be avoided in processing extruded AZ61 alloy.

Acknowledgments This work was financially supported by the National Science and Technology Major Project of China (No. 2012ZX04012011), the National Natural Science Foundation of China (No. 51375306) and the National Basic Research Program of China (No. 2011CB012903).

\section{References}

[1] B.L. Mordike, T. Ebert, Mater. Sci. Eng. A 302, 37 (2001)

[2] Z. Zhen, M. Qian, S. Ji, Z. Fan, Scr. Mater. 54, 207 (2006)

[3] A. El-Morsy, A. Ismail, M. Waly, Mater. Sci. Eng. A 486, 528 (2008)

[4] I.S. Yasnikov, A. Vinogradov, Y. Estrin, Scr. Mater. 76, 27 (2014)

[5] S. Spigarelli, E. Cerri, P. Cavaliere, E. Evangelista, Mater. Sci. Eng. A 327, 144 (2002)

[6] J.J. Jonas, R.A. Holt, Acta Metall. 24, 911 (1976)

[7] S.L. Semiatin, G.D. Lahoti, Metal. Trans. A 12, 1719 (1981)

[8] Y. Sun, L.X. Hu, J.S. Ren, Mater. Charact. 100, 163 (2015)

[9] S.V.S. Narayana Murty, B. Nageswara Rao, J. Phys. D Appl. Phys. 31, 3306 (1998)
[10] J.C. Shao, B.L. Xiao, Q.Z. Wang, Z.Y. Ma, Y. Liu, K. Yang, Mater. Sci. Eng. A 527, 7865 (2010)

[11] X. Li, S. Lu, K. Wang, M.W. Fu, C. Cao, Mater. Sci. Eng. A 576, 256 (2013)

[12] W. Guo, Q. Wang, H. Zhou, J. Alloys Compd. 558, 164 (2013)

[13] P. Wanjara, M. Jahazi, H. Monajati, S. Yue, J.P. Immarigeon, Mater. Sci. Eng. A 396, 50 (2005)

[14] H. Monajati, M. Jahazi, S. Yue, A.K. Taheri, Metall. Mater. Trans. 36A, 895 (2005)

[15] T. Kil, J. Lee, Y. Moon, Procedia Eng. 81, 298 (2014)

[16] G.R. Ebrahimi, A. Momeni, S.M. Abbasi, H. Monajatizadeh, Met. Mater. Int. 19, 11 (2013)

[17] S.M. Abbasi, A. Momeni, Mater. Sci. Eng. A 552, 276 (2012)

[18] S.V.S. Narayana Murty, B. Nageswara Rao, Mater. Sci. Eng. A 254, 76 (1998)

[19] S.V.S. Narayana Murty, B. Nageswara Rao, B.P. Kashyap, Int. Mater. Rev. 45, 15 (2000)

[20] S. Anbuselvan, S. Ramanathan, Mater. Des. 31, 2319 (2010)

[21] Y. Kim, S.H. Lee, S. Lee, J.W. Noh, Mater. Sci. Eng. A 552, 276 (2012)

[22] D.H. Hou, S.M. Liang, R.S. Chen, C. Dong, E.H. Han, Acta Metall. Sin. (Engl. Lett.) 28, 115 (2015)

[23] R.C. Zeng, L.J. Liu, T.T. Pang, F. Zhang, W.W. Zhang, S.Q. Li, H.Z. Cui, E.H. Han, Acta Metall. Sin. (Engl. Lett.) 28, 373 (2015)

[24] S.L. Semiatin, J.J. Jonas, Formability and workability of metals: plastic instability and flow localisation (American Society for Metals, Metals Park, 1987), p. 51

[25] W.Y. Jiang, T. Chen, L.P. Wang, Y.C. Feng, Y. Zhu, K.F. Wang, J.P. Luo, S.W. Zhang, Acta Metall. Sin. (Engl. Lett.) 26, 473 (2013)

[26] D. Samantaray, S. Mandal, A.K. Bhaduri, Mater. Des. 32, 716 (2011)

[27] Y.G. Miao, B.T. Wu, X.F. Xu, D.F. Han, Acta Metall. Sin. (Engl. Lett.) 27, 1038 (2014) 